\title{
Control of a Mobile Robot Through Brain Computer Interface*
}

\section{Control de Móvil Robótico Mediante Interfaz Cerebro Computador}

DOI: http://dx.doi.org/10.17981/ingecuc.11.2.2015.08

Research article - Reception Date: January 30, 2015 - Acceptance Date: September 16, 2015

\author{
Robinson Jiménez Moreno \\ Master in Industrial Automation. GAV Group, Universidad Militar Nueva Granada - UMNG. \\ Bogotá (Colombia). robinson.jimenez@unimilitar.edu.co \\ Jorge Rodríguez Alemán \\ Student of Mechatronics Engineering. GAV Group, Universidad Militar Nueva Granada - UMNG. \\ Bogotá (Colombia). roboticanaval@hotmail.com
}

To reference this paper:

R. Jiménez Moreno and J. Rodríguez Alemán., "Control of a Mobile Robot Through Brain Computer Interface," INGE CUC, vol. 11, no. 2, pp. 74-83, 2015. DOI: http://dx.doi.org/10.17981/ingecuc.11.2.2015.08

\begin{abstract}
This paper poses a control interface to command the movement of a mobile robot according to signals captured from the user's brain. These signals are acquired and interpreted by Emotiv EPOC device, a 14-electrode type sensor which captures electroencephalographic (EEG) signals with high resolution, which, in turn, are sent to a computer for processing. One brain-computer interface (BCI) was developed based on the Emotiv software and SDK in order to command the mobile robot from a distance. Functionality tests are performed with the sensor to discriminate shift intentions of a user group, as well as with a fuzzy controller to hold the direction in case of concentration loss. As conclusion, it was possible to obtain an efficient system for robot movements.
\end{abstract}

Keywords - Brain Computer Interface -BCI, Emotiv Epoc, Mobile Robot, Arduino, EEG.

\begin{abstract}
Resumen - En este artículo se presenta una interfaz de control que permite comandar el movimiento de un robot móvil en función de la captura de señales provenientes del cerebro del usuario. Dichas señales son adquiridas e interpretadas por medio del dispositivo Emotiv Epoc, el cual cuenta con 14 sensores tipo electrodo que captan señales electroencefalográficas (EEG) de alta resolución, que después son enviadas a un equipo de cómputo para ser procesadas. Se desarrolla una interfaz cerebro-computador (BCI) basada en el software y SDK del desarrollador del Emotiv mediante la cual se comanda de forma remota el robot móvil. Se realizan pruebas de funcionalidad con el sensor para discriminar una intención de desplazamiento por parte de un grupo de usuarios y un controlador difuso para sostener la dirección en casos de perdida de la concentración. Como conclusión, se logra obtener un sistema eficiente para la manipulación del robot.
\end{abstract}

Palabras clave - Interfaz Cerebro Computador, Emotiv Epoc, Robot Móvil, Arduino, EEG.

\footnotetext{
"Research article derived from the research project: "Control de un móvil robótico mediante señales de EEG". Funded by the Vicerectorate of Research of the Universidad Militar Nueva Granada. Starting date: July, 2014. Compleition date: December, 2014.
} 


\section{INTRODUCTION}

Human interaction with its environment is determined by the perception people have of their surroundings; in turn, this perception is defined by the sensory experience abstracted through the senses. This abstraction takes place in the brain, and it is here where the signals that will allow any action are produced. By means of the current technology available, one way to interact with the environment is through Brain-Computer Interfaces (BCI). This type of interface offers a more natural manner of controlling mechatronic prostheses, for instance. A BCI is based on the neuronal activity from the brain; this is captured through a series of sensors and processed by a computer later with the objective of generating a stimulus or control action over a physical and distant device [1].

Many are the developments regarding BCI. An analysis of the algorithms required between the EEG signal capture and the establishment of useful data for a BCI is explored in [2], where the large amount of evidence allows focusing on applications based on these algorithms. In [3], a review of the feasible applications for BCI use is carried through; among these fields are control and communication, entertainment, and motor substitution and recovery control systems.

Amidst the applications found in the literature review, some novelties as the one presented in [4], where a BCI aimed at teaching tasks to a humanoid robot regarding object manipulation (e.g. according to visual characteristics as color) are put forward. In [5], an application to manipulate an avatar in a virtual environment using a BCI is posed. More specialized applications are used as control support for people's movements [6]. In this case, a portable exoskeleton was created; it used commands received by the EEG sensor Emotiv EPOC, which is an EEG signal capture device, and created a BCI that provided the instructions for the exoskeleton's movements.

The Emotiv EPOC has been used in numerous applications involving BCI, among them [7], [8], [9], [10], [11], and [12] stand out. This peripheral's potential distinguishes EEG signals by capturing them through 14 electrode sensors that allow the identification of different intentions from a user's thoughts.

This paper expounds the use of this sensor for a BCI application that seeks to control the direction in the displacement of a mobile robot: forward, backward, left, and right movement in agreement with the user's thoughts. A fuzzy controller is added to ease abrupt actions from the mobile's engines when the movement intention is lost or confusing.

This work constitutes the progress of a research carried out by the group regarding the inclusion of mechatronic systems in medicine, where robotic agents have started to be included for teleoperation
[13] and some manners to achieve a more natural control of them are being explored. In this sense, BCI improvements are perceived as tools for a natural handling between the user and a mechatronic system.

The paper is divided into five sections: section II explains the development of the BCI for signal acquisition through Emotiv Epoc; section III describes how the previous data is used to control the mobile robot, as well as the techniques applied provided the movement's control signal is lost; section IV sets forth the results obtained from the movement trials of the mobile using the BCI; and finally, conclusions are posed in section $\mathrm{V}$.

\section{Methods and Materials}

This section introduces the materials used for the development of this BCI. These are: the Emotiv Epoc headset, the software of the development, the communication system, and the mobile robot.

The Emotiv Epoc is a multi-sensorial headset with 14 electrodes and two references. It receives the EEG signals from the user's brain. In the beginning, Emotiv Epoc was launched as an innovative control system for videogame interaction. Fig. 1 shows the Emotiv Epoc, and its main characteristics are explained in [14]

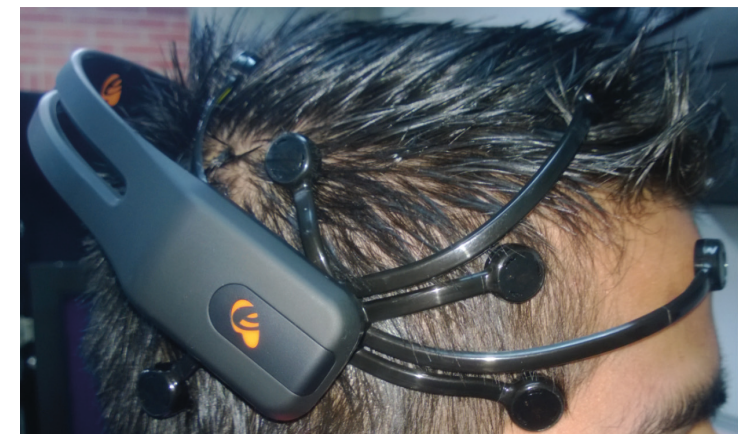

Fig. 1. Emotiv Epoc Headset. Source: Author.

The human brain emits waves with certain patterns as a result of external stimuli or mental states; amongst the main waves produced the following stand out: alpha, beta, theta, gamma, and delta. Alpha waves range between the 8 and $12 \mathrm{~Hz}$ and they are related to imaginative, creative, and meditative states. Beta waves, 12 to $30 \mathrm{~Hz}$, involve concentration, stress, or excitement states. Theta waves, between the 4 and $7 \mathrm{~Hz}$, are present during relaxation and deep meditation. Delta waves, 0.5 to $4 \mathrm{~Hz}$, represent the deep stage of sleep; and gamma waves, 25 to $100 \mathrm{~Hz}$, are present during high level information processing states. The operation of Emotiv Epoc is based on the recognition and translation of such brain waves. 
Regarding the software, it can be divided into three parts: the EmoComposer, the Cognitiv Detection Suite, and the Visual Studio. Emotive developer provides an SDK (Software Development Kit) for Windows with a software called EmoComposer, which depending on the signals received from the sensor allows determining the state of each electrode and interpreting the information generated by the user as of the brain waves; these are received as numeric values corresponding to the different intentions of the user. The application's environment is observed in Fig. 2, where the main development features are illustrated and a learning training can be generated for different kinds of users.

Another Emotiv environment is the Cognitiv Detection Suite. This software permits the assessment of the brain waves information in real time with the purpose of differentiating every attempt for completing an action on a real or virtual object. Once the system is trained in these matters, the pertinent signals are received to be characterized as direction commands for the mobile's intended movement.

For the integration of the BCI and the controlled hardware, an application was developed on Visual Studio (Fig. 3) where an algorithm was programed to, first, capture the EmoComposer's information, and then, process and send it in a serial manner to the communications module of the mobile command in accordance with the user's intentions to guide the mobile.

Fig. 4 shows the EmoComposer's output string generated by simulating a cognitive intention of the user, in this case, a forward move.

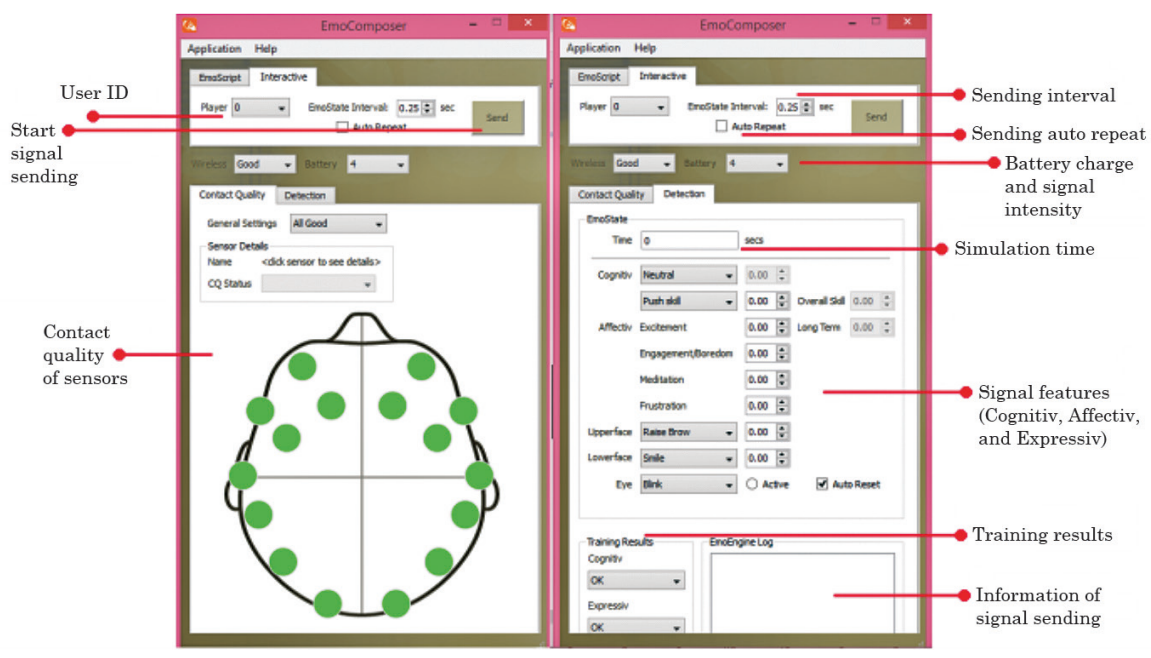

Fig. 2. EmoComposer Environment. Source: Author.

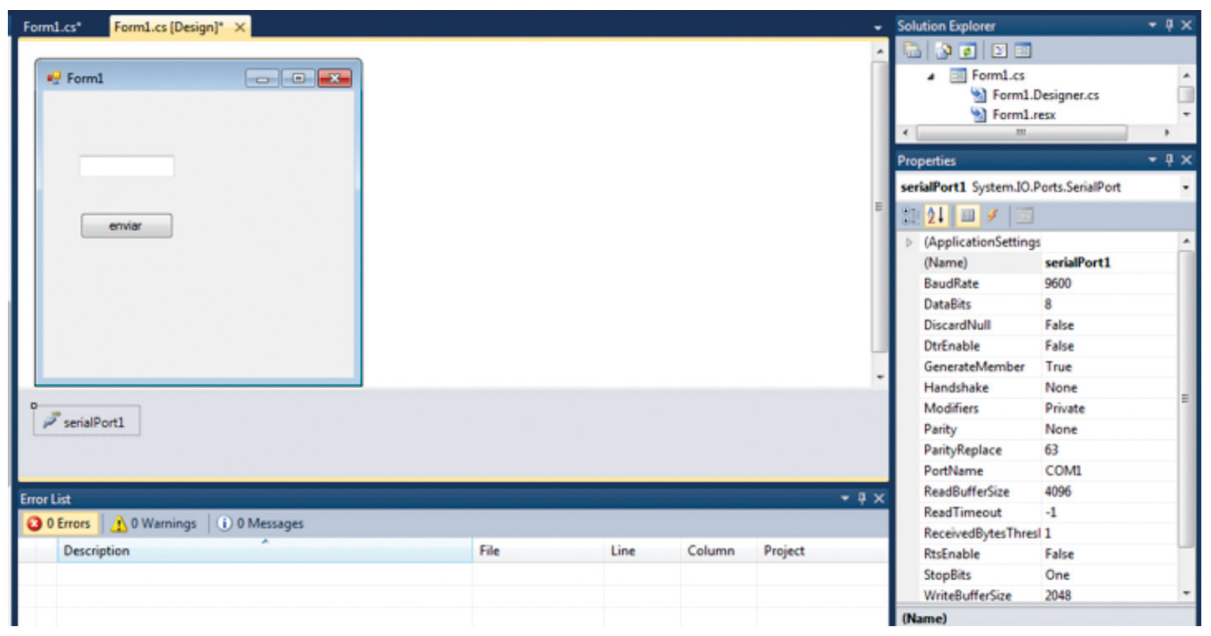

Fig. 3. Visual Studio Environment for Serial Transmission. Source: Author. 


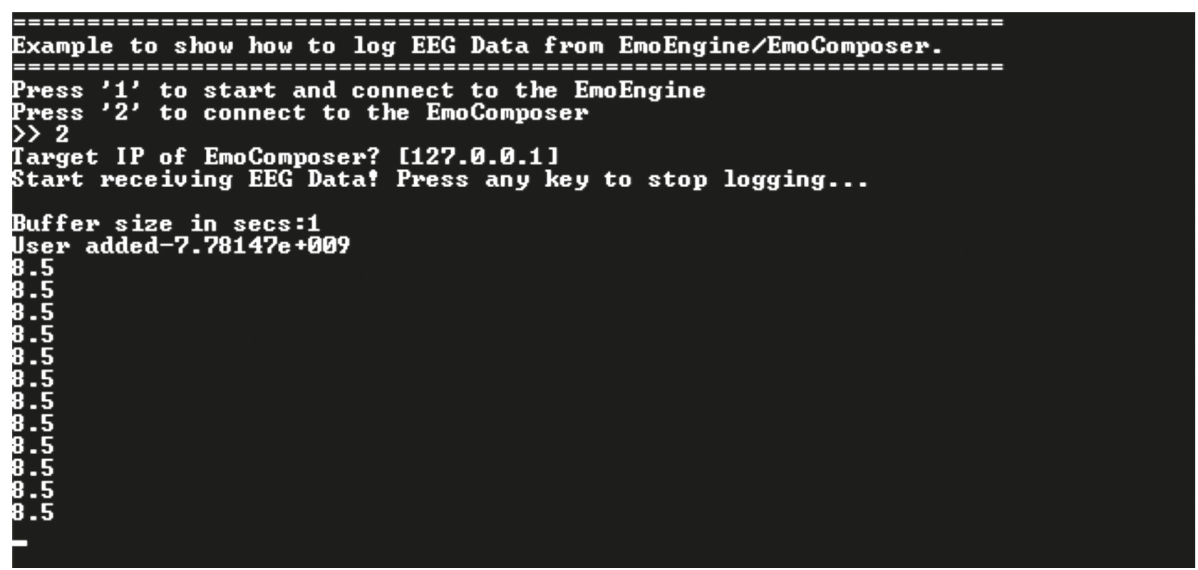

Fig. 4. Forward Action Simulation through EmoComposer. Source: Author.

A RS232 protocol system entitles communication between the BCI and the mobile robot. In this system the brain signals values that correspond to the respective displacement directions of the mobile are delivered through an 8-bit frame to an XBee Pro series1 radiofrequency module, which in turn, operates with an IEEE 802.15.4 standard. XBee has a transmission power of $60 \mathrm{~mW}$, a receiver sensitivity of $-100 \mathrm{dBm}$, and a range of $1 \mathrm{~km}$ in open spaces Two devices are used, the transmitter and the receiver, in a simplex communication where only the BCI sends information to the mobile.

The mobile device moves thanks to two DC engines attached to each wheel, thus, this mobile has a differential configuration with a central rotating wheel which can move freely. This can be appreciated in Fig. 5.

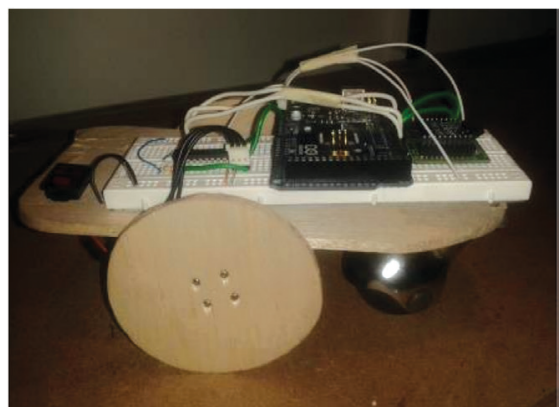

Fig. 5. Mobile Robot. Source: Author.

As the mobile robot has a differential configuration, (1) presents the kinematic model that describes this functioning [15].

$$
\left[\begin{array}{c}
\dot{X} f \\
\dot{Y f} \\
\dot{\varphi f}
\end{array}\right]=\left[\begin{array}{cc}
-\frac{r}{2} \operatorname{sen} \varphi & -\frac{r}{2} \operatorname{sen} \varphi \\
\frac{r}{2} \cos \varphi & \frac{r}{2} \cos \varphi \\
\frac{r}{b} & -\frac{r}{b}
\end{array}\right] *\left[\begin{array}{l}
\theta 1 \\
\theta 2
\end{array}\right]
$$

The mobile's control system is based on a microcontrolled Arduino MEGA 2560 board with the following features:

- Microcontroller ATmega328

- Operating voltage of $5 \mathrm{~V}$

- Digital 14-pin I/O (6 may provide PWM output)

- 6 pins for analog input

- $40 \mathrm{~mA}$ DC current per I/O pin

- Flash Memory 32 KB

- 1 UART port

- 1 KB EEPROM memory (ATmega328)

- $16 \mathrm{MHz}$ Clock Speed

This board's low cost and small size were important selection factors. Additionally, this board fulfills the project's needs since it provides two PWM channels, one for each engine, and a serial port to receive direction control signals.

\section{III.Movement Control}

In order to establish the mobile's movements, Emo Control Panel was adopted so as to define the corresponding levels for the actions executed by the user when guiding the robot. The system was represented through a virtual cube that moves forward, backwards, to the left, and to the right, in accordance with the manipulation possibilities of the mobile robot. The different values for the discrimination of each action are represented in Table I.

Table I. Decision Thresholds for Direction

\begin{tabular}{|c|c|}
\hline ACTION & VALUE \\
\hline FORWARD & 2 \\
\hline BACKWARD & 4 \\
\hline LEFT & 32 \\
\hline RIGHT & 64 \\
\hline
\end{tabular}

Source: Author 
Fig.6 shows the result of thinking about a forward movement in terms of the virtual cube visualiztion (left); the EEG information panel and the sensor distribution are also displayed (right). For the forward movement intention, the activation signals correspond to the AF3, F7, F8, and AF4 sensors.

Likewise, Fig. 7 illustrates the backward movement of the cube, for this reason, the orange facet of the cube covers the entire animation screen. Emotiv sensors evidence the highest amplitude response in AF4, a high peak when compared to F8, F4,
FC6, T8, T7, F3, and F7 sensors, which in turn, present a significant amplitude variation regarding the remaining sensors.

Fig. 8 exemplifies the behavior for a left movement intention. An important and uniform variation in all the sensors is observed, however, a difference in the timing is manifested; sensors AF4, F4, FC6, and $\mathrm{T} 8$ respond sooner than the rest.

For a right turn, shown in Fig. 9, higher response values are appreciated in sensors $\mathrm{AF} 4, \mathrm{~F} 8, \mathrm{~F} 4, \mathrm{FC} 6$, T8, and F8; the amplitudes in this case are rather low if compared to the previous actions.

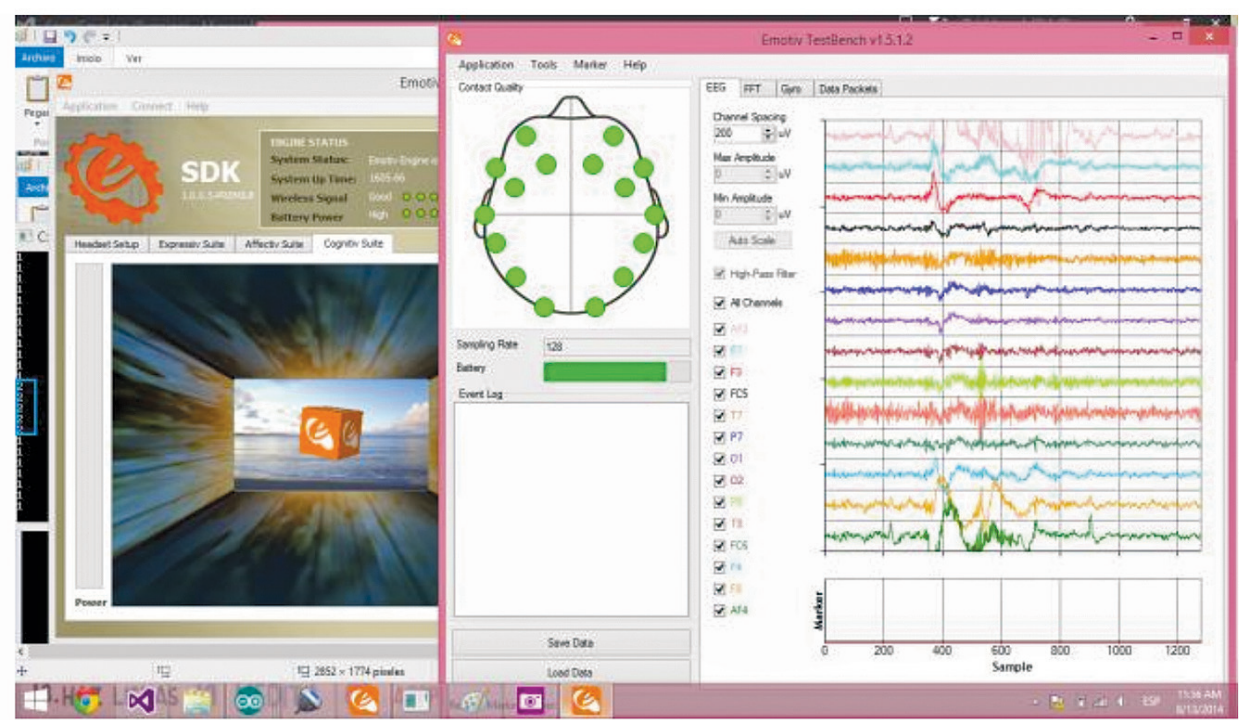

Fig. 6. Forward Movement. Source: Author.

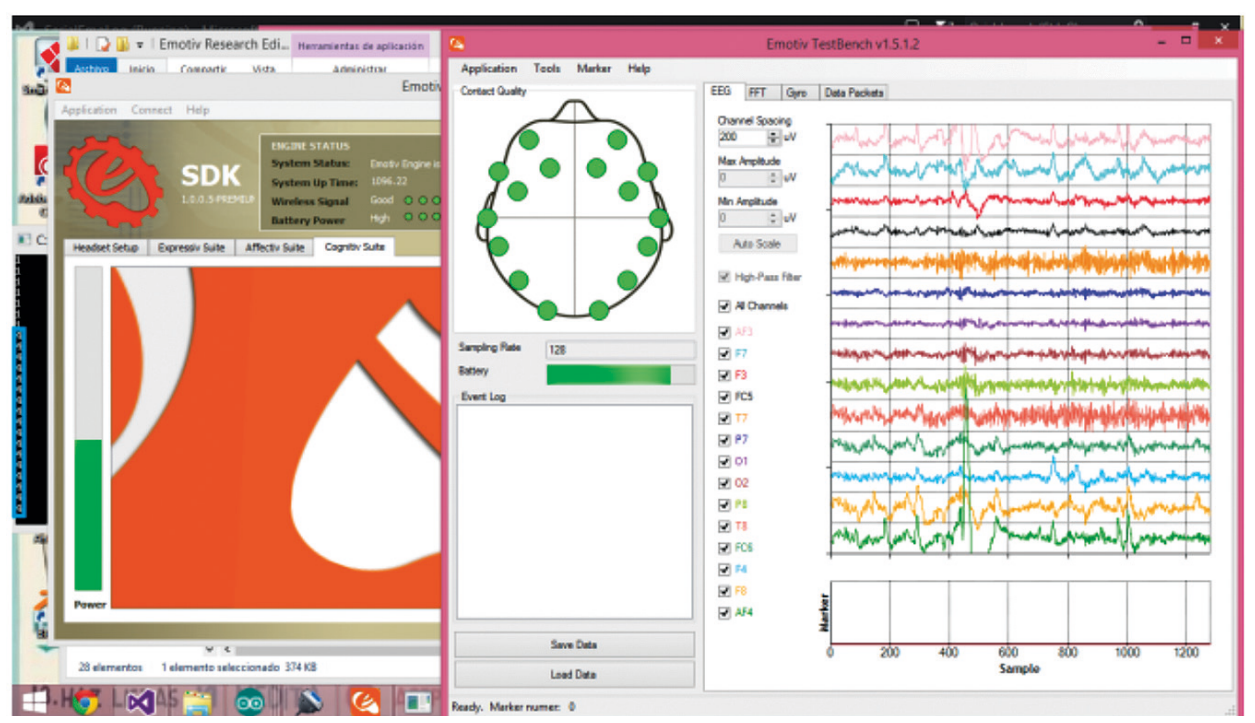

Fig. 7. Backward Movement. Source: Author. 


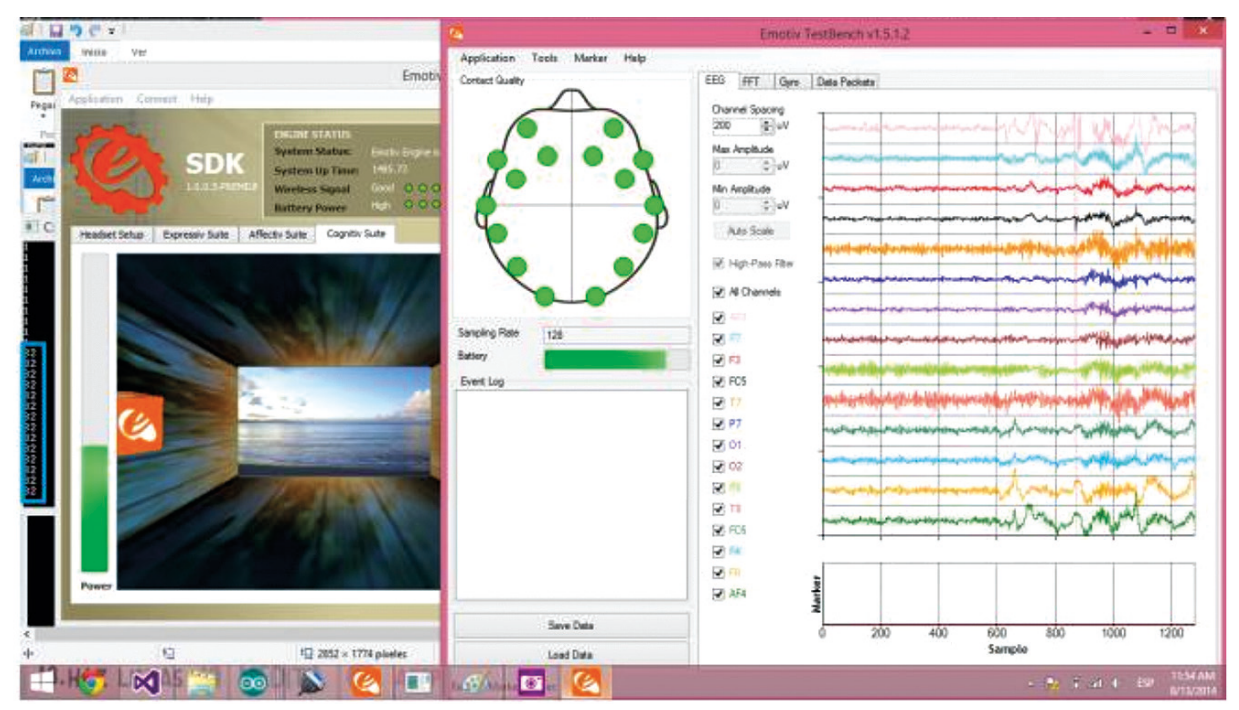

Fig. 8. Left Movement. Source: Author.

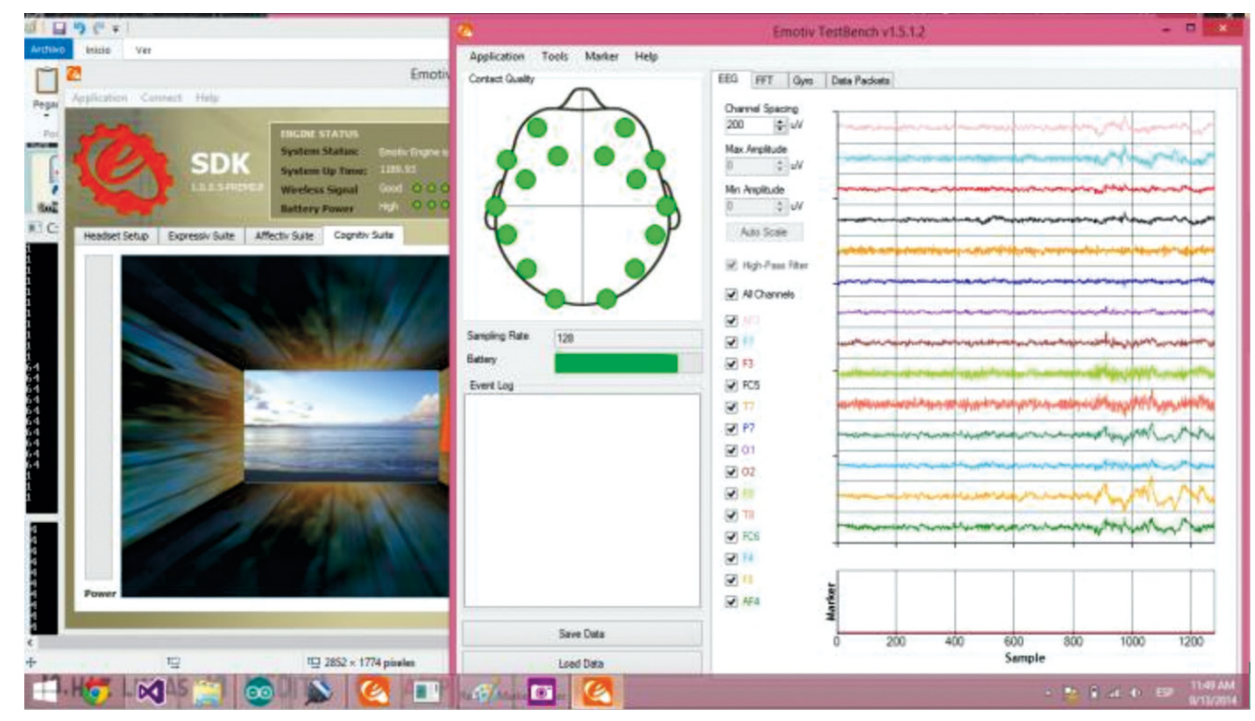

Fig. 9. Right Movement. Source: Author.

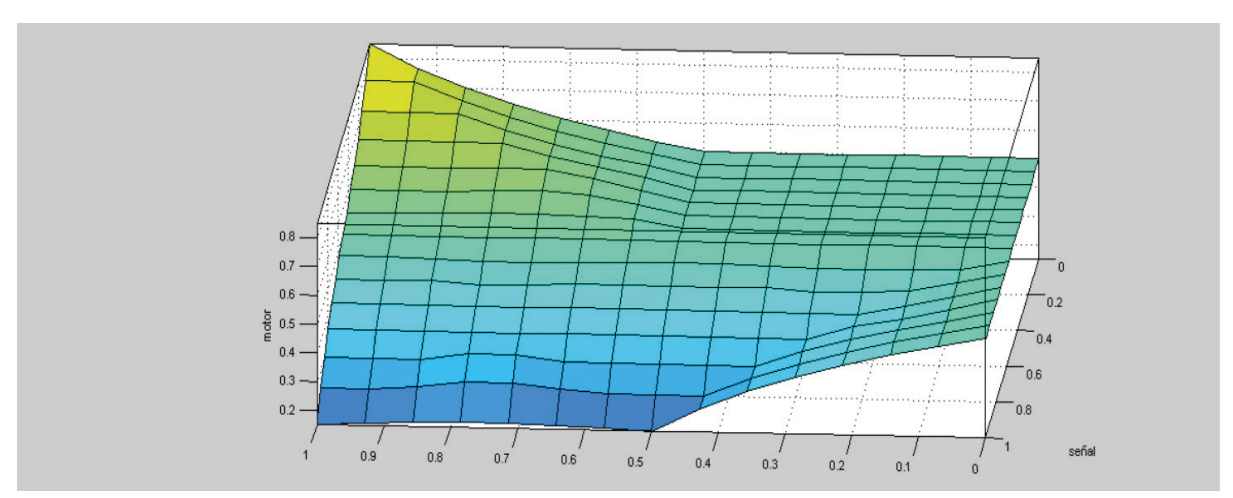

Fig. 10. Surface View. Source: Author. 
Since movement, derived from a user's thought, requires concentration in order to be recognized and a suitable intensity of the signals captured by the electrodes, sometimes there might be a lack of signal reception or confusion in the intention of movement. To reduce these obstacles, a fuzzy supervision system is implemented to check on signal presence, if the signal requires enduring or changing, or if on the contrary, there is signal absence. For this, the control surface shown in Fig. 10 is applied.

The basis of rules regulating this surface are illustrated in Fig. 11 and they are related to the duration of time in which the control signal is being received (or not) and the type of signal. The domain of discourse for input and output has three functions: for time, the linguistic tags are little, medium, and much; for signal, no signal, hold, and change; and for output, stop, continue, change.

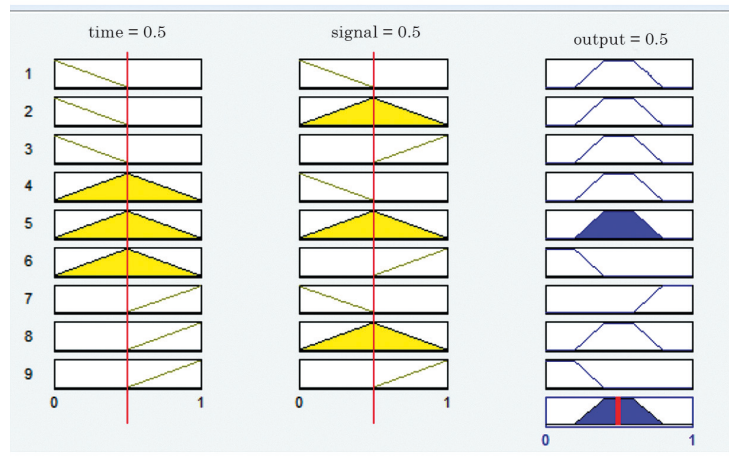

Fig. 11. Basis of Rules. Source: Author.

The basis of rules implementation for the fuzzy controller is included within the microcontrol system by using Mamdani's inference algorithm, as indicated in [16].

\section{RESULTS}

To validate the effectiveness of the implemented interface, the direction control is tested initially for each of the characterizations attained. Fig. 12 to Fig. 15 show the testing process for each threshold found in the BCI training, hence, allowing a forward (Fig. 12), left (Fig. 13), backward (Fig. 14), and right (Fig. 15) movements.

Concerning the mobile's manageability, the discrimination ability for the desired movements is assessed. For this, a 10-repetition exercise is carried through for each movement and five users. Results are presented in Table II.

Table II. Repetition Test for BCI Users

\begin{tabular}{|l|l|l|l|l|}
\hline & RIGHT & LEFT & FORWARD & BACKWARD \\
\hline USER 1 & 9 & 8 & 9 & 7 \\
\hline USER 2 & 8 & 7 & 9 & 8 \\
\hline USER 3 & 7 & 8 & 8 & 7 \\
\hline USER 4 & 8 & 8 & 9 & 9 \\
\hline USER 5 & 9 & 9 & 8 & 9 \\
\hline AVERAGE & 8.2 & 8 & 8.6 & 8 \\
\hline
\end{tabular}

Source: Author

As it can be observed, average values evidence an $80 \%$ of success rate in user's intention identification. For a constant right movement and a sudden signal lost, the controller holds the current course.

Once witnessed that the BCI allowed guiding the mobile in accordance with the user's intention, a test route was outlined to assess its performance in the face of different kinds of users (Fig. 16).

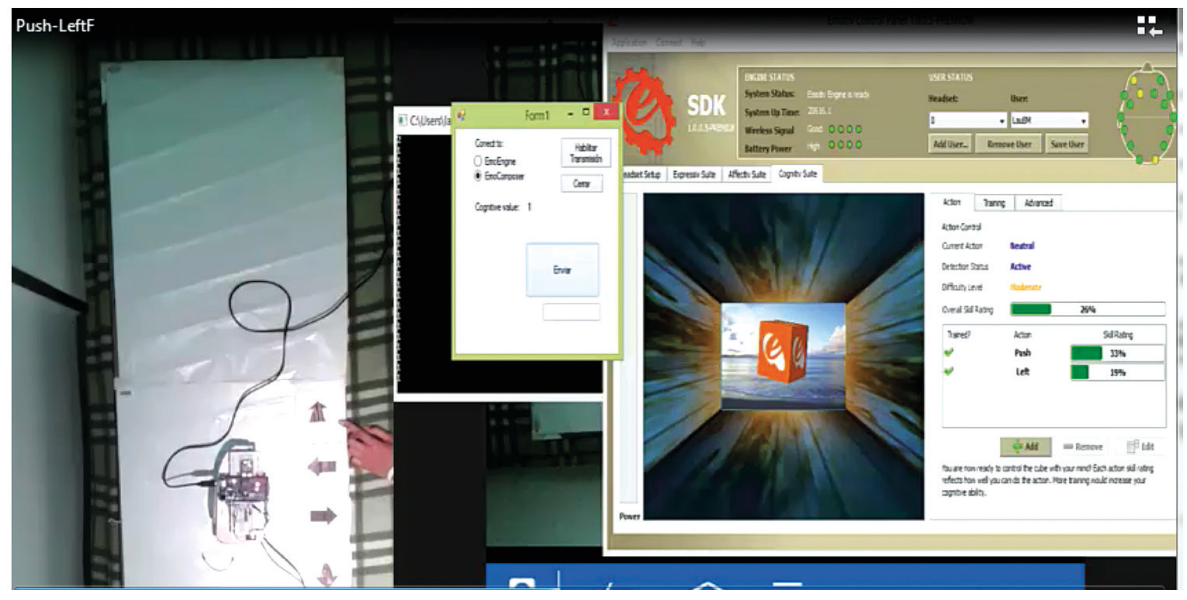

Fig. 12. Forward Movement. Source: Author. 


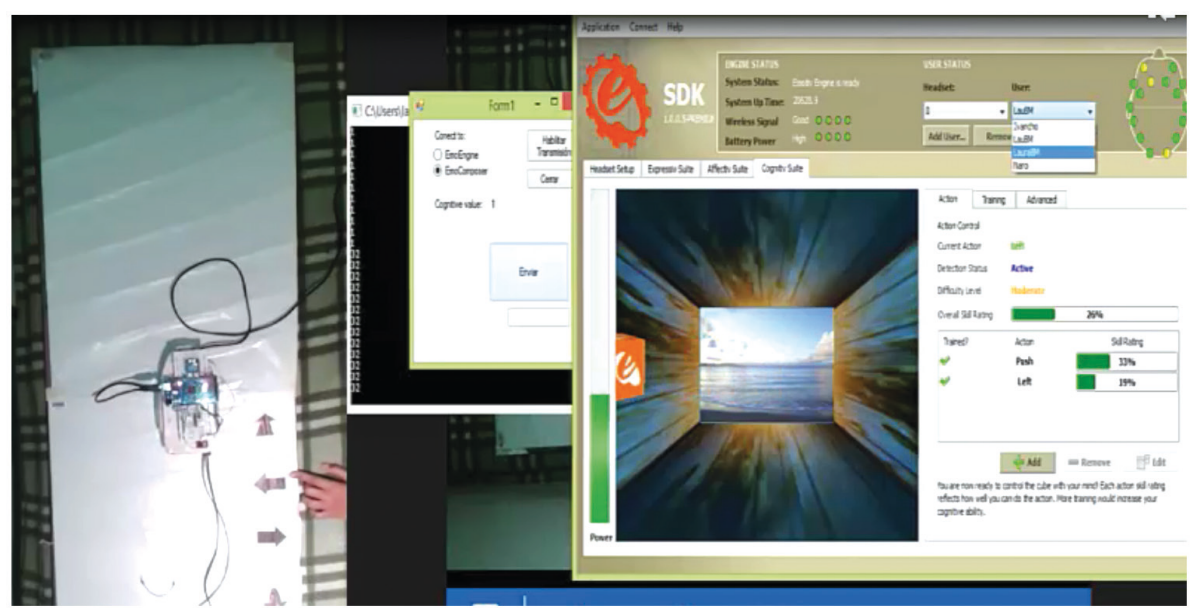

Fig. 13. Left Movement.

Source: Author.

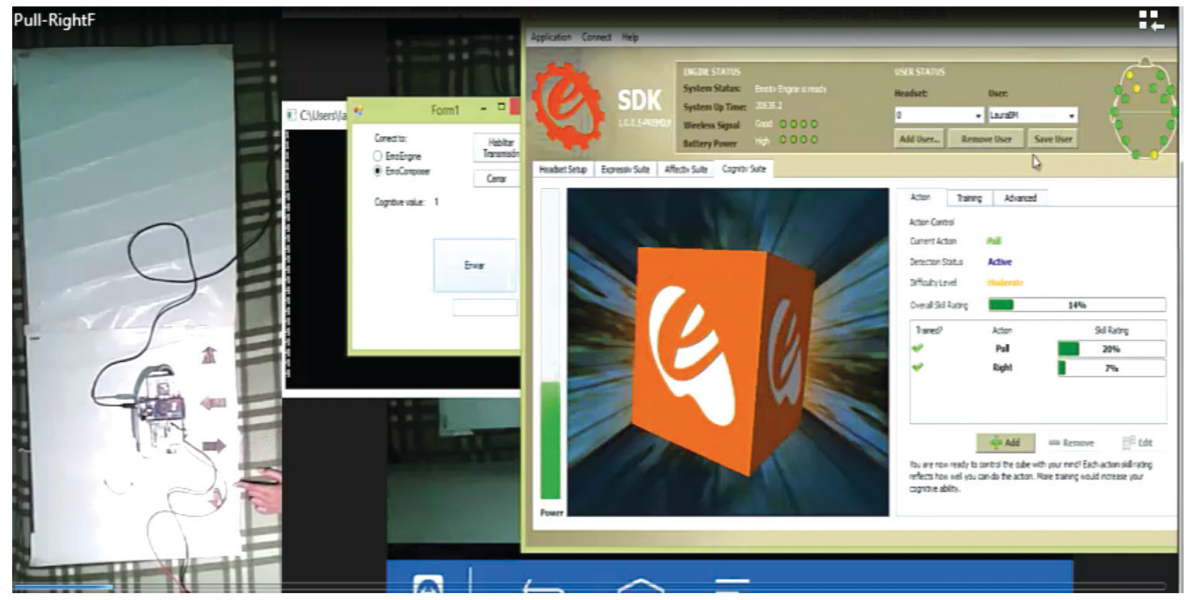

Fig. 14. Backward Movement.

Source: Author.

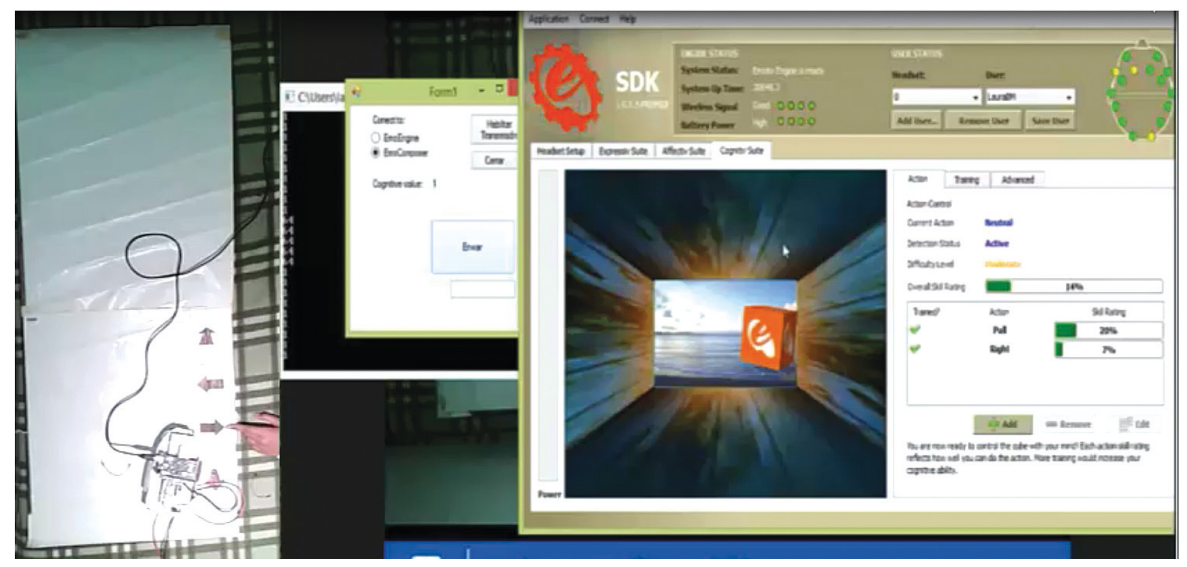

Fig. 15. Right Movement.

Source: Author. 


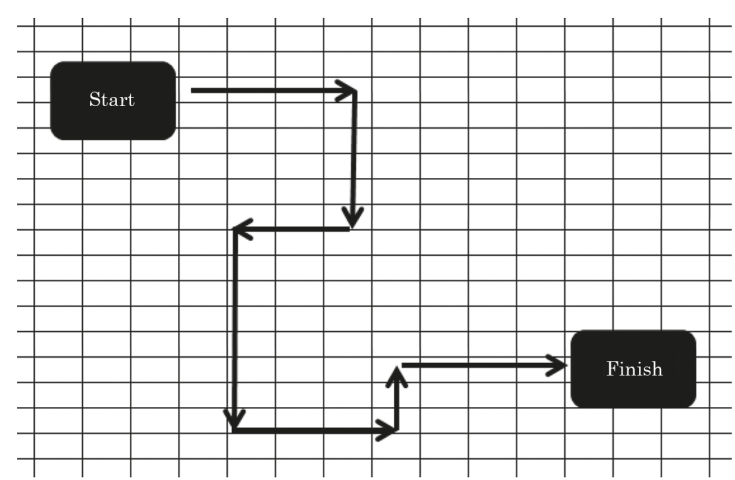

Fig. 16. Test Route.

Source: Author

Time and deviation percentage was measured for the five users (Table III). The highest precisions (accurately following the established route) are related to higher time values due to concentration and response requirements from the user. However, the user with the least time value (30 s) was able to finish the route with a good precision level.

Table III. User's BCI Response

\begin{tabular}{|l|l|l|l|l|l|}
\hline User & 1 & 2 & 3 & 4 & 5 \\
\hline Time (seg) & 35 & 43 & 30 & 35 & 46 \\
\hline Precision (\%) & 90 & 90 & 84 & 91 & 94 \\
\hline
\end{tabular}

Source: Author.

Control signals received through Cognitiv Detection Suite software do not vary significantly among users; this means, users activate the same regions, but concentration levels produce activation threshold variations, thus, deriving in a different control action for each user.

\section{Conclusions}

An Emotive Epoc-based BCI was implemented to control the movements of a mobile robot using thoughts. This sensor demonstrated its effectiveness for the command of mechatronic systems.

A fuzzy interface system avoided random shifts of the mobile provided the original intention was not identified; likewise, it allowed gradual direction changes for a more accurate control of the movements.

There were not significant variations in BCI use among users, although a different control level in each user was observed. This difference is linked to shape variations in the brain waves between users. However, this did not affect the thresholds established during the training process for each direction shift; hence, route completion was accomplished by every user.
A future pragmatic application for this interface can be oriented for wheelchair control by disabled people.

\section{REFERENCES}

[1] B. He, S. Gao, H. Yuan, and J. R. Wolpaw, "Brain-Computer Interfaces," in Neural Engineering, 2nd ed., New York: Springer, 2013, pp. 87-151.DOI: 10.1007/978-14614-5227-0_2

[2] F. Lotte, M. Congedo, A. Lécuyer, F. Lamarche, and B. Arnaldi, "A review of classification algorithms for EEGbased brain-computer interfaces.," J. Neural Eng., vol. 4, no. 2, pp. R1-R13, Jun. 2007. DOI: 10.1088/1741 2560/4/2/R01

[3] J. D. R. Millán, R. Rupp, G. R. Müller-Putz, R. MurraySmith, C. Giugliemma, M. Tangermann, C. Vidaurre, F Cincotti, A. Kübler, R. Leeb, C. Neuper, K.-R. Müller, and D. Mattia, "Combining Brain-Computer Interfaces and Assistive Technologies: State-of-the-Art and Challenges.," Front. Neurosci., vol. 4, Jan. 2010. DOI: 10.3389/ fnins.2010.00161

[4] C. I. Penaloza, Y. Mae, M. Kojima, and T. Arai, "BMI-based framework for teaching and evaluating robot skills," in 2014 IEEE International Conference on Robotics and Automation (ICRA), 2014, pp. 6040-6046. DOI: 10.1109/ ICRA.2014.6907749

[5] B. B. Longo, A. B. Benevides, J. Castillo, and T. BastosFilho, "Using Brain-Computer Interface to control an avatar in a Virtual Reality Environment," in 5th ISSNIP. IEEE Biosignals and Biorobotics Conference (2014): Biosignals and Robotics for Better and Safer Living (BRC), 2014, pp. 1-4. DOI: 10.1109/BRC.2014.6880960

[6] J. Webb, Z. G. Xiao, K. P. Aschenbrenner, G. Herrnstadt, and C. Menon, "Towards a portable assistive arm exoskeleton for stroke patient rehabilitation controlled through a brain computer interface," in 2012 4th IEEE RAS \& EMBS International Conference on Biomedical Robotics and Biomechatronics (BioRob), 2012, pp. 1299-1304. DOI: 10.1109/BioRob.2012.6290674

[7] M. Perakakis and A. Potamianos, "Affective evaluation of a mobile multimodal dialogue system using brain signals," in 2012 IEEE Spoken Language Technology Workshop (SLT), 2012, pp. 43-48. DOI: 10.1109/ SLT.2012.6424195

[8] E. J. Rechy-Ramirez, H. Hu, and K. McDonald-Maier, "Head movements based control of an intelligent wheelchair in an indoor environment," in 2012 IEEE International Conference on Robotics and Biomimetics (ROBIO), 2012, pp. 1464-1469. DOI:10.1109/ROBIO.2012.6491175

[9] A. G. Risangtuni and A. Widyotriatmo, "Towards online application of wireless EEG-based open platform Brain Computer Interface," in 2012 IEEE Conference on Control, Systems \& Industrial Informatics, 2012, pp. 141144. DOI: 10.1109/CCSII.2012.6470489

[10] Y. Liu, X. Jiang, T. Cao, F. Wan, P. U. Mak, P.-I. Mak, and M. I. Vai, "Implementation of SSVEP based BCI with Emotiv EPOC," in 2012 IEEE International Conference on Virtual Environments Human-Computer Interfaces and Measurement Systems (VECIMS) Proceedings, 2012, pp. 34-37. DOI: 10.1109/VECIMS.2012.6273184.

[11] N. Chumerin, N. V. Manyakov, M. van Vliet, A. Robben, A. Combaz, and M. Van Hulle, "Steady-State Visual Evoked Potential-Based Computer Gaming on a Consumer-Grade EEG Device," IEEE Trans. Comput. Intell. AI Games, vol. 5, no. 2, pp. 100-110, Jun. 2013. DOI: 10.1109/TCIAIG.2012.2225623

[12] N. S. M. Puzi, R. Jailani, H. Norhazman, and N. M. Zaini, "Alpha and Beta brainwave characteristics to binaural beat treatment," in 2013 IEEE 9th International Colloquium on Signal Processing and its Applications, 2013 , pp. 344-348. DOI: 10.1109/CSPA.2013.6530069 
[13] R. J. Moreno, F. E. Valcárcel, and D. A. Hurtado, "Teleoperated systems: a perspective on telesurgery applications (Sistemas teleoperados: una perspectiva desde las aplicaciones en telecirugía/ Sistemas de teleoperação: uma perspectiva sobre aplicações telecirurgia)," Revista Ingeniería Biomédica, vol. 7, no. 14. 14-Jan-2014.

[14] Emotiv Epoc \& testbench ${ }^{\mathrm{TM}}$ specifications, Emotiv, 2014. Emotiv Software Development Kit User Manual for Release, Ed . 1.0.0.5.
[15] L. Ríos and M. Bueno, "Modelo matemático para un robot móvil,” Sci. Tech., vol. 1, no. 38, pp. 13-18, Jun. 2008.

[16] R. J. Moreno, O. A. Sánchez, and O. L. R. Sandoval, "Análisis de la implementación de un controlador difuso sobre diferentes arquitecturas de hardware.," Ciencia e Ingeniería Neogranadina, vol. 23, no. 1. pp. 77-87, 06Jun-2013. 